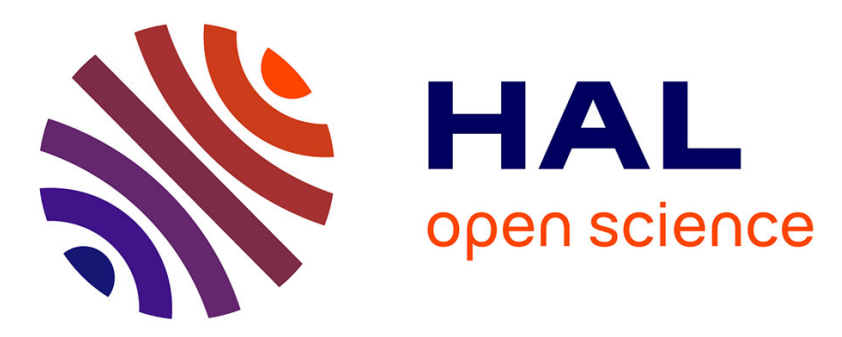

\title{
Evolution of the metal and metalloid content along the bioethanol production process
}

\author{
Carlos Sanchez, Jean Paul Vidal, Charles-Philippe Lienemann, José-Luis \\ Todolí
}

\section{> To cite this version:}

Carlos Sanchez, Jean Paul Vidal, Charles-Philippe Lienemann, José-Luis Todolí. Evolution of the metal and metalloid content along the bioethanol production process. Fuel Processing Technology, 2018, 173, pp.1-10. 10.1016/j.fuproc.2018.01.001 . hal-01859458

\section{HAL Id: hal-01859458 \\ https://hal.science/hal-01859458}

Submitted on 22 Aug 2018

HAL is a multi-disciplinary open access archive for the deposit and dissemination of scientific research documents, whether they are published or not. The documents may come from teaching and research institutions in France or abroad, or from public or private research centers.
L'archive ouverte pluridisciplinaire HAL, est destinée au dépôt et à la diffusion de documents scientifiques de niveau recherche, publiés ou non, émanant des établissements d'enseignement et de recherche français ou étrangers, des laboratoires publics ou privés. 


\section{Evolution of the metal and metalloid content}

\section{along the bioethanol production process}

Carlos Sánchez, ${ }^{a}$ Jean-Paul Vidal ${ }^{b}$, Charles-Philippe Lienemann, ${ }^{c}$ Jose-Luis Todolía*

${ }^{a}$ Department of Analytical Chemistry, Nutrition and Food Sciences, P.O. Box 99, 03080,

Alicante, Spain.

bUNGDA, 174, boulevard Camelinat, F-92247 Malakoff

CIFP Energies Nouvelles, Rond-point de l'échangeur de Solaize, BP 3, F-69360 Solaize,

France 


\section{Abstract}

Metal concentration has been determined through inductively coupled plasma mass spectrometry for bioethanol samples, raw materials employed to obtain this biofuel and samples taken from different critical points of the production process. In this way it has been possible to study the evolution of the elemental content all along the bioethanol production process, and to establish the origin of the metals present in the final samples, on the other. Moreover, the steps of the production process where metals were either removed from the biomass or accumulated in the biofuel were identified.

Four different acid sample treatments were compared through the analysis of two biomass certified reference materials (CRM) and. the analytical procedure was validated by means of CRMs analysis. The results revealed that, for the most suitable method (nitric acid microwave digestion), recoveries for the analytes of interest went from $90 \%$ to $110 \%$. Furthermore, good short-term and long-term precision and acceptable limits of detection (LOD) were obtained.

Two different production lines were studied and slight differences were detected in terms of concentration of minor elements $(\mathrm{Cd}, \mathrm{Co}, \mathrm{Sb}, \mathrm{Pb}$ and $\mathrm{V})$. The raw material was identified as the most important source of metals found in the final samples. Meanwhile the distillation step caused 1000 to 10000 times decrease in metals concentration in the final bioethanol as compared to the initial biomass.

Keywords: bioethanol, metals, production process, biomass, ICP-MS 
1. Introduction.

Recently, biofuels have been considered as an effective alternative energy source due to the health and environmental problems caused by fossil fuels together with the increasing demands for energy and the depletion of petroleum in the near future.[1-3] Among the large number of biofuels, bioethanol is one of the most promising product, largely because its use can reduce up to $75 \%$ the emission of greenhouse gases (GHG), as $\mathrm{CO}_{2}, \mathrm{CH}_{4}$ and $\mathrm{N}_{2} \mathrm{O}$, compared with fossil fuels.[1-5] Consequently, its production and consumption have grown exponentially during the last two decades.[6]

Bioethanol can be used in its pure form within modified spark-ignition engines or blended with petrol, this blend is known as ethanol-fuel. One liter of ethanol contains $66 \%$ of the energy provided by a liter of petrol but it is used in the blend as a very efficient octane-boosting agent, thereby substituting for toxics or chemical additives such as methyl terc-buthyl ether (MTBE).[1,3,7]

Although the synthesis process depends strongly on the raw material, the production of bioethanol generally includes the following steps: (i) preparation of the feedstock to achieve maximum yield of sugar content; (ii) hydrolysis of the feedstock and extraction of the sugars; (iii) production of solutions with high sugar concentrations (syrups); (iv) fermentation to convert sugars into ethanol; $(v)$ distillation, which is one of the most important process in terms of pollutants and water removal; and, (vi) dehydration, that is carried out to obtain the ethanol concentration required (anhydrous ethanol or hydrated ethanol).[2,4]

Several industrial processes have been developed to achieve the bioethanol production, appearing different generations of bioethanol. The first-generation 
bioethanol is the alcoholic product generated from sugars (sugar cane, sugar beet, etc.), seeds or starch (potato, corn, wheat, etc.) using microorganisms. Generally, the yeasts convert sugars in ethanol by fermentation and, after that, the distillation and the dehydration are carried out.[7] Although the process is simple and efficient due to its relatively ease of converting sugars and starch to ethanol, only a reduced part of the plant is used to obtain bioethanol. This causes the main problem of these kind of processes, related to the fuel-food competition.[1,7,8] The second-generation bioethanol appears to overcome this problem and its production involves a previous enzymatic hydrolysis of agricultural lignocellulosic biomass employed as raw material, which is non-edible food crop production or whole plants biomass. The main advantages of the second generation are that it avoids the fuel-food competition and the low cost of the raw material, which is wasted in other processes $[2,7,9]$. However, the equipment required to obtain this type of bioethanol is more sophisticated and the yield reached is lower than that obtained in the first-generation processes [7]. Finally, a third generation of biofuels is being developed. Although the third-generation biofuels are being implemented quickly in the case of biodiesel [10], this emerging technology is still not widely used for bioethanol production.

At the end of the production process, bioethanol may contain organic as well as inorganic pollutants, among them metals.[11-14] The appearance of these metallic species can affect notably the quality of the product. Some of them, as $\mathrm{Pb}, \mathrm{Tl}, \mathrm{Hg}, \mathrm{Cd}$ or As, can cause health problems even at low concentrations. $[4,15,16]$ Heavy metals are considered an important risk for the environment.[17-20] Finally, other metals, as Fe or $\mathrm{Cu}$, can damage the vehicle engines and modify the stability of the ethanol. $[4,21]$ 
It is not easy to establish clearly the origin of metals in bioethanol. Some authors reported that they can appear during fuel transportation and storage $[4,15,17,21,22]$ or may be added to the final bioethanol as additive $[4,18]$. However, other works have suggested that the main source of metals in bioethanol is the raw material $[4,21,23-$ 26]. Thus, the metal content depends on the atmospheric pollution and the soil where the raw material has grown.[15,25] Additional works have reported that bioethanol can also be contaminated during its production process. $[17,21,23]$

Several works have been focused on the development of analytical methodologies to carry out the determination of metals in both bioethanol $[4,12,13]$ and the raw materials employed to obtain this biofuel [24-26], especially when they have been cultivated in a soil contaminated with heavy metals [25]. The main conclusion of these works is that a large number of elements were found, at rather low concentrations being $\mathrm{Na}, \mathrm{Fe}, \mathrm{Ni}, \mathrm{Co}, \mathrm{Cu}$ and $\mathrm{K}$ considered as major elements $[4,12,13]$. However, the number of papers focused on the monitoring of metals along the bioethanol production process is limited and there exist a lack of knowledge in this regard.

The aim of this work was thus to evaluate the fate of metals initially present in the biomass raw material along real bioethanol production processes. This study would get more insight into the possible sources of contamination during this process as well to establish the origin of metals finally present in bioethanol samples. In order to achieve these goals, an analytical methodology based on samples digestion followed by analysis through ICP-MS was developed and validated to finally apply it to the analysis of thirty-two real samples collected from two different processes. 
2. Experimental.

2.1. Reagents and standards.

Nitric acid 65\% suprapure grade (Merck, Darmstadt, Germany), hydrochloric acid 30\% suprapure grade (Merck, Darmstadt, Germany) and hydrogen peroxide 33\% w/v (110 vol.) stabilized (Panreac, Barcelona, Spain) were employed for the digestion of the samples.

Four series of multielement standards were prepared from stock solutions to obtain the calibration curves for the analytes of interest: (i) Merck IV solution (Merck, Darmstadt, Germany); (ii) ICP-200.8-1 solution (High purity standards, Charleston, USA); and, (iii) Ca standards were used to obtain the calibration line for this analyte since the calibration with Merck IV solution was not possible because of the spectral interferences caused by ${ }^{88} \mathrm{Sr}^{2+}$ on ${ }^{44} \mathrm{Ca}^{+}$and ${ }^{86} \mathrm{Sr}^{2+}$ on ${ }^{43} \mathrm{Ca}^{+}$. These three sets of calibration standards were prepared with a solution containing $5 \%$ of nitric acid prepared by proper dilution of nitric acid $65 \%$ suprapure with ultrapure water $(R>18.2$ $M \Omega$ ) obtained with a water purification system (Millipore, Texas, USA). The blank for the three calibration lines was the aqueous solution with $5 \%$ of nitric acid, whereas procedural blanks were obtained for each digestion. Standards and blanks were filtered with a $0.45 \mu \mathrm{m}$ PTFE filter pore size (Filabet, Barcelona, Spain).

\subsection{Bioethanol production process and samples.}

Thirty-two samples taken along a sugar and bioethanol production processes implemented in a real factory were analyzed. The process studied in the present work is shown in Figure 1. Initially, the pieces of raw material (beetroot) were cut in slices (samples type A) to improve the sugar extraction during the next step and the liquid 
generated during the sliced process was collected (samples type B). In the second step, the sugars and other compounds (i.e., metals and organic compounds) were extracted using water at $70-80^{\circ} \mathrm{C}$ generating several kinds of juices (samples type $\mathrm{C}$ ) and the wet material was mechanically pressed and the juice obtained (samples type D) was mixed with those obtained previously. The juice collected (mixture of samples type B, C and D) was treated with calcium hydroxide at temperatures between $40^{\circ} \mathrm{C}$ and $75^{\circ} \mathrm{C}$ (liming) before the addition of carbon dioxide into the solution (carbonatation). The main purpose of these two steps was to remove the metals extracted from the raw material by means of precipitation of insoluble hydroxides and carbonates. After that, the purified juice 1 was heated. Once water was partially evaporated (samples type E), a new liming at $85^{\circ} \mathrm{C}$ and carbonatation generated a cleaner juice (samples type $\mathrm{F}$ ). In the next step, this juice was heated to generate a syrup with no more than $30 \%$ of water and high concentration of sugars (samples type G). After that, some crystallization processes were proposed to obtain sugars from this solution and the rest of the solution was collected and centrifuged. This new syrup (EP2) contained less than $25 \%$ of water (samples type H). EP2 was introduced in the fermentation tank and the yeast contained promoted the fermentation process thus giving rise to ethanol causing a depression in the sugars content. Finally, distillation took place obtaining the final bioethanol (samples type J) and the heaviest residue of the distillation process (i.e., vinasse) was used as fertilizer (samples type I).

The samples, provided by the French company UNGDA, were obtained from two different sugar factories located in the center and the east part of France. The sampling procedure was done at the beginning and at the end of the production campaign. 


\subsection{Samples pre-treatment.}

Several pre-treatments involving centrifugation, dilution and filtration were tested for liquid samples. However, they were not successful due to the presence and/or formation of suspended solids in the samples. Furthermore, solid samples required a digestion pre-treatment.

Four different digestion pre-treatments were tested and compared for two CRMs: a conventional digestion at atmospheric pressure in a hot plate and three methods based on microwave digestions using different reagents. For the digestion in a hot plate, $5 \mathrm{~mL}$ of nitric acid $65 \%$ were added to $0.25 \mathrm{~g}$ of sample and the mixture was heated at $90^{\circ} \mathrm{C}$ for 1 hour in open glass vessels. The microwave digestion was carried out by adding three different acid solutions to $0.25 \mathrm{~g}$ of sample: (i) $8 \mathrm{~mL}$ of nitric acid 65\%; (ii) $7 \mathrm{~mL}$ of nitric acid $65 \%$ and $1 \mathrm{~mL}$ of hydrogen peroxide $33 \%$; and, (iii) $6 \mathrm{~mL}$ of nitric acid $65 \%$ and $2 \mathrm{~mL}$ of hydrochloric acid $30 \%$. In all the cases, the temperature program consisted of a heating step from room temperature to $200^{\circ} \mathrm{C}$ at a constant rate during $15 \mathrm{~min}$ keeping the final temperature constant for $15 \mathrm{~min}$. After the digestion treatment, the volume of the resulting solution was made up to $25 \mathrm{~mL}$ with ultrapure water. All the solutions were filtered with a $0.45 \mu \mathrm{m}$ PTFE filter pore size (Filabet, Barcelona, Spain) at room temperature. Real samples, in turn, were digested using nitric $65 \%$ before performing their analysis.

\subsection{Instrumentation.}

A microwave oven Start D (Milestone, Bergamo, Italy) was employed to carry out the samples digestion under controlled pressure and temperature under conditions described in section 2.3. 
An Agilent Technologies 7700x ICP-MS spectrometer (Santa Clara, California, USA) equipped with a high matrix introduction system (HMI) was employed to take the ionic intensities of the analytes shown in Table 1. A Scott spray chamber thermostated at $-2^{\circ} \mathrm{C}$ and a micronebulizer Micromist ${ }^{\circledR}$ (Glass Expansion, Melbourne, Australia) were established as the sample introduction system. The operating conditions and the isotopes quantified are gathered in Table 1.

2.5. Method validation and samples analysis.

Two biomass certified reference materials (CRM), SRM ${ }^{\circledR}$ 1575a (NIST, Maryland, USA) and DC73349 (NACIS, Beijing, China), were employed for method validation. Besides, fifteen spiked real samples and a quality control containing $100 \mathrm{ppb}$ of Merck IV multielement solution (Merck, Darmstadt, Germany) were inserted in the sequence of samples and randomly analyzed to evaluate both, the recoveries obtained in real matrices and the intraday precision. The long-term accuracy and precision was evaluated by means of the analysis of twelve samples that were digested and analyzed with a time gap of three months.

The samples were digested according to the pre-treatment described in 2.3 and they were analyzed by ICP-MS after dilution at an analyte dependent factor. Every sample was digested and analyzed in triplicate. The bioethanol samples (samples J, Figure 1) were analyzed through ICP-MS according a methodology based on external calibration with ethanol/water standards and a total sample consumption system (high temeperature Torch Integrated Sample Introduction System, hTISIS) [12].

3. Results and discussion. 
3.1. Evaluation of the four sample pre-treatment methods.

The results obtained for the two CRMs analyzed are shown in Table 2 and Table 3. Silicon is present in the CRM SRM1575a at $0.6 \%$ and it was not completely digested with any of the approaches studied (Table 3). For this reason, the evolution of Si along the process was not studied. Besides, the use of a conventional digestion under atmospheric pressure in open beakers induced systematic errors for several elements. Sodium, boron and barium concentrations were overestimated in CRM DC73349 (Table 2) when the conventional digestion was employed. This could be originated by pollution from the glass containers as an ionic exchange equilibrium was produced between the sample and the surface of the borosilicate glass. [27] Moreover, it should be considered that the contamination suffered by each sample was affected by the specific glass employed, the analytes concentration in the sample and their chemical form. Thus, the found concentrations of $\mathrm{Na}, \mathrm{B}$ and $\mathrm{Ba}$ in CRM SRM 1575a (Table 3), agreed with the certified values because they were present at rather high levels. Other elements, as vanadium, nickel, iron, copper and arsenic provided concentrations statistically lower than the certified values what was assigned to the losses of volatile species and/or non-completed digestion. These results motivated the selection of a microwave based digestion method for pre-treating real samples.

Sodium concentrations found in CRM DC73349 after applying the three microwave digestions were slightly higher than the certified level. This could reveal an extra source of contamination. The use of mixed reagents did not provide any further improvement in terms of recovery as compared with the use of only nitric acid. Furthermore, the use of hydrochloric acid or hydrogen peroxide provided higher 
signals for the procedural blanks than those obtained when only nitric acid was employed. Hence, microwave digestion of $0.25 \mathrm{~g}$ of sample with $8 \mathrm{~mL}$ of nitric acid was applied as general pre-treatment for all the real samples.

Additionally, carbon ICP-MS signals were monitored for each digestion procedure and they were compared against those obtained for the corresponding procedural blanks. In the case of microwave treatment methods, carbon ionic intensities were statistically similar to those observed for procedural blanks. Meanwhile, in the case of conventional digestion, dissolved samples provided higher carbon signals than procedural blanks. This fact supported the hypothesis of a non-completed digestion in the case of a conventional acid treatment methodology.

\subsection{Analytical figures of merit.}

The instrumental limits of detection (LODs) were obtained according to the $3 \mathrm{sb} / \mathrm{m}$ criterion where $\mathrm{s}_{\mathrm{b}}$ corresponded to the standard deviation of ten consecutive blank measurements. The LODs for real samples (Table 4) were obtained considering the mass of sample and the final volume of the solution after the digestion procedure.

Inter-day and intra-day precisions were also evaluated. For this purpose, eleven replicates of a QC standard were computed every hour during the sequence, whereas twelve representative samples were selected and the complete analytical procedure was applied to them three months later. In the case of intra-day precision, the relative standard deviation ranged from $2.6 \%$ to $6.9 \%$ depending on the isotope. For inter-day studies, $t$ paired test was applied for each analyte. The t-values calculated for all the elements quantified were below the tabulated Student-t for a $95 \%$ confidence level and 11 freedom degrees (i.e., 2.228). Thus, the methodology based on the samples 
microwave digestion with nitric acid and the further ICP-MS analysis by using external calibration provided acceptable precision and a satisfying repeatability.

\subsection{Recovery test.}

The recoveries were determined for twelve real matrices. For this purpose, samples were spiked with the analytes of interest and they were analyzed. The added concentration of each analyte was adapted according to the concentration range found in the samples. Additionally, the found concentrations in the non-spiked samples were subtracted to those obtained for the spiked ones. The samples employed in this section were selected based on their representativeness of the complete bioethanol production process. Figure 2 shows the recoveries obtained for each element in a box chart. All the recovery values were included within the 80 to $120 \%$ range. Meanwhile, the mean values ranged between $90 \%$ and $110 \%$. These results confirmed that matrix effects did not affect the analytical results and the method was accurate (and precise) enough to quantify metals and metalloids in bioethanol related samples.

3.4. Analysis of real samples. Metal evolution along the production process.

As mentioned before, two sets of samples coming from different sugar/bioethanol factories were studied in the present work. Although both are based on the same production process (Figure 1), some differences existed between them. In the refinery 1 , six points of the process (twelve samples) were analyzed whereas in the process 2 ten points were monitored (twenty samples). The results found for the two treatment plants will be shown separately in order to discern whether variables such as the 
geographical origin of the raw materials and/or the particular characteristics of the factory (i.e., different critical points) affected the metal content and its evolution throughout the production process. However, it should be mentioned that the samples were collected from a production process that is continuously working and the juices and syrups analyzed were not necessarily coming from the same pieces of raw material as this is not a continuous process. The quality of the raw material might change over time and this might explain some differences. Nonetheless, these samples can be employed to obtain clear conclusions about the possible origin of metals in bioethanol as well as to establish general trend regarding the evolution of these metals along the production process.

\section{Sugar refinery/bioethanol no. 1}

Six types of samples were analyzed: raw material (A), juices (C), pressing juices (D), syrup (G), vinasse (I) and bioethanol (J). Each step of the process is described in 2.2.

Figure 3 shows the evolution of the concentration of those elements present above the LOQ from the raw material (beetroot) to vinasse (Figure 1). The elemental concentration in bioethanol samples is not represented as the metals were present at very low concentrations in the final product compared to raw material and intermediate samples. Several interesting conclusions could be drawn from Figure 3. The major metals present in the raw material were $\mathrm{Na}, \mathrm{Mg}, \mathrm{Ca}$ and $\mathrm{K}$ (Figure 3.a and Figure 3.b). They were found at concentrations going from 0.1 to $2.2 \mathrm{~g} \mathrm{~kg}^{-1}$. Other elements such as $\mathrm{Al}$ and Fe (Figure 3.c) were present at levels of tens of $\mathrm{mg} \mathrm{kg}^{-1}$ whereas $\mathrm{Mn}, \mathrm{Zn}, \mathrm{Sr}$ and $\mathrm{Ba}$ concentrations went from 1 to $7 \mathrm{mg} \mathrm{kg}^{-1}$ (Figure $3 . \mathrm{d}$ and Figure 3.e). Additional minor elements, as $\mathrm{Co}, \mathrm{Ni}, \mathrm{Pb}, \mathrm{Mo}, \mathrm{Sb}$ and $\mathrm{Cd}$ (Figure 3.f, Figure 
3.g and Figure 3.h), were found in the raw material at levels in the order of tens of $\mu \mathrm{g}$ $\mathrm{kg}^{-1}$. Some of these metals were also typically encountered in bioethanol samples, although they were in concentrations lower than $1 \mathrm{mg} \mathrm{kg}^{-1}$ for major metals and tens of $\mu \mathrm{g} \mathrm{kg}-1$ of trace elements.[4,12,13]

As an additional interesting finding, it was clearly noticed that, for $\mathrm{Na}$ and $\mathrm{K}$, the concentration in the juice and pressing juice was similar to that found in the raw material. Note that these elements are usually present in biomass under ionic form.[24] Therefore, they can be efficiently extracted in water at $80^{\circ} \mathrm{C}$ (See Figure 1). In contrast, for the remaining elements, the concentration decreased drastically in the extraction step, thus indicating that their extractability in hot water was lower than for $\mathrm{Na}$ and $\mathrm{K}$. However, Figure 3 reveals that $\mathrm{Mo}, \mathrm{Sb}, \mathrm{Ba}, \mathrm{Co}$ and $\mathrm{Mg}$ were more efficiently extracted than $\mathrm{Ca}, \mathrm{Mn}, \mathrm{Zn}, \mathrm{Al}, \mathrm{Fe}, \mathrm{Sr}, \mathrm{Ni}, \mathrm{Cd}$ and $\mathrm{Pb}$. Although this behavior was shown in beetroot raw material, it could not be extrapolated to any kind of biomass since, for a given element, the extraction yield in hot water would depend on its chemical form.[24]

Another interesting phase is the syrup formation and purification (Figure 1). Juice and pressing juice are mixed and limed with $\mathrm{Ca}(\mathrm{OH})_{2}$ and subsequently carbonated with $\mathrm{CO}_{2}$. These two steps are supposed to remove major metals forming insoluble carbonates and hydroxides. The extent of this reaction depends on the solubility product constant, $\mathrm{K}_{\mathrm{sp}}$, of each formed salt. Obviously, for a given elemental concentration, the carbonates and hydroxides precipitation with the consequent metal removal, is favored as $\mathrm{K}_{\mathrm{sp}}$ becomes lower. This constant is in fact very low in the case of divalent and trivalent ions whereas carbonates and hydroxides of monovalent 
cations show high solubility. In this regard, $\mathrm{K}$ and $\mathrm{Na}$ concentrations increase around ten times during this step (Figure 3.a). This is because, on the one hand, $\mathrm{K}$ and $\mathrm{Na}$ carbonates and hydroxides have a high solubility and, on the other hand, water evaporates partially thus leading to a reduction in the total volume. Meanwhile, the rest of the major elements as $\mathrm{Ca}, \mathrm{Mg}, \mathrm{Al}, \mathrm{Fe}, \mathrm{Ba}$ and $\mathrm{Sr}$ are removed from the syrup through insoluble salts precipitation (Figure 3.b, c and e). Additional metals whose solubility product constants were low, such as $\mathrm{Co}, \mathrm{Ni}$ or $\mathrm{Pb}$, showed a notable rise in their concentration (Figure 3.f and g). This fact could be explained considering that their concentrations in the juice were actually low and, hence, the product of concentrations (e.g., [metal] $\times\left[\mathrm{CO}_{3}{ }^{2-}\right]$ ) was lower than the solubility constant. As a result, these metals did not form insoluble salts and their growth in concentrations was a consequence of water evaporation.

Finally, distillation is considered to be the most critical step in terms of metals removal. In the frame of the present study, it was found that the concentration of $\mathrm{Na}, \mathrm{K}, \mathrm{Ca}$ and $\mathrm{Mg}$ (major elements) in the obtained bioethanol was in the order of hundreds of $\mu \mathrm{g} \mathrm{kg}$ ${ }^{1}$ and below $10 \mu \mathrm{kg}^{-1}$ for the rest of the elements. This meant that the elemental concentrations in the final product decreased by three orders of magnitude as compared to those found in the intermediate products of the process. Although similar elemental concentrations could be expected in syrup and vinasse samples, the concentrations for $\mathrm{Na}, \mathrm{K}, \mathrm{Mn}, \mathrm{Zn}, \mathrm{Co}, \mathrm{Ni}, \mathrm{Pb}$ and $\mathrm{Mo}$ found in vinasse were in the same order of magnitude to those obtained in the intermediate products and lower than those found in syrup (see Figure 1). A possible explanation to these results would be the precipitation suffered by some elements after distillation. 
Focusing on the comparison of the found concentrations of metals in the samples collected at the beginning and at the end of the campaign, it could be concluded that, in general terms, there were differences neither in their evolution along the production process nor in the determined values. Only $\mathrm{Pb}$ (Figure 3.g) and Ni (Figure 3.f) concentrations were significantly different as a function of the raw material. However, in both cases the extracted amount of both metals was virtually the same.

\section{Sugar refinery/bioethanol no. 2}

As regards the second bioethanol production refinery, two sets of samples were analyzed: ten samples were collected at the beginning and ten at the end of the production campaign. These samples corresponded to: raw material (A), juice obtained from the sliced raw material (B), extraction juices (C), pressing juice (D), juice heated after first pre-liming and carbonatation (E), juice purified (F), syrup (G), EP2 (H), vinasse (I) and bioethanol (J) (Figure 1). Each step of this process is described in section 2.2.

Although the general trends observed in this process were similar to those shown by the samples coming from refinery 1 , samples $B, E, F$ and $H$ were not available in the previous process and they can be helpful for understanding the evolution of metals along the bioethanol production process. Figure 4 shows the evolution of the contents for elements detected at concentrations above $1 \mathrm{mg} \mathrm{kg}^{-1}$ in raw material samples ( $\mathrm{Na}$, $\mathrm{K}, \mathrm{Ca}, \mathrm{Mg}, \mathrm{Al}, \mathrm{Fe}, \mathrm{Sr}, \mathrm{Ba}, \mathrm{Mn}$ and $\mathrm{Zn})$. The corresponding results for elements found at concentrations in the order of tens or hundreds of $\mu \mathrm{g} \mathrm{kg}^{-1}$ are plotted in Figure 5 (Co, $\mathrm{Ni}, \mathrm{Sb}$ and $\mathrm{Mo}$ ). Previous reports revealed the presence of all these elements in bioethanol samples. $[4,12,13]$ 
The concentrations found in the raw material were similar to those obtained in the samples collected from factory number 1 . Considering the slicing process, it can be observed that a higher fraction of some metals was extracted at the beginning of the campaign than at its end. This fact can be clearly observed for Fe and Al (Figure 4.c). In the first step of the process, the raw material is cut and separated in two different fractions: slices and the corresponding juice (Figure 1). As a result, metals can partially migrate to the juice. In fact, it was observed that the Fe and Al concentrations in the raw material pieces at the beginning of the campaign were much lower than those obtained at its end whereas the opposite trend was shown for the juice obtained from sliced biomass. This trend was observed in spite to the fact that, along the campaign, the raw material came from different soils and, hence, they might have different elemental composition.

After the raw material was cut, metals were partially extracted with hot water and the solid residue was mechanically pressed. The trends observed in the extraction could be extrapolated from the results obtained for refinery 1 . Thus, $\mathrm{Na}$ and $\mathrm{K}$ were more efficiently extracted than the rest of metals.

In the next step of the bioethanol production process, liming and carbonatation procedures were applied to the blend of three products: juice from slice, juice from extraction and pressing juice (Figure 1). This mix was heated at moderate temperature in order to obtain a solution with $84 \%$ of water. Note that in the initial juices, water content went from 86 to $95 \%$. As it was observed in the case of samples from refinery 1, two groups of elements were distinguished: (i) elements removed from the juices through precipitation of insoluble carbonates and hydroxides $(\mathrm{Mg}, \mathrm{Ca}, \mathrm{Fe}, \mathrm{Al}, \mathrm{Sr}, \mathrm{Ba}$, 
$\mathrm{Mn}$ and $\mathrm{Zn}$ ); and, (ii) elements that remained dissolved in the solution because either, their carbonates and hydroxides were soluble ( $\mathrm{Na}$ and $\mathrm{K}$ ), or they were present in the raw material at actually low concentrations ( $\mathrm{Sb}, \mathrm{Mo}$, Co and $\mathrm{Ni}$ ). After the first purification step, a second liming at $85^{\circ} \mathrm{C}$ and carbonatation took place and, as in in the previous purification step, the concentration of $\mathrm{Ca}, \mathrm{Mg}, \mathrm{Fe}, \mathrm{Al}, \mathrm{Sr}, \mathrm{Ba}, \mathrm{Zn}$ and $\mathrm{Mn}$ decreased (Figure 4) whereas those for $\mathrm{Na}$ and $\mathrm{K}$ remained unaltered. However, this purification step appeared to cause the partial removal of $\mathrm{Co}, \mathrm{Ni}$ and Mo (Figure 5). This was expected, taking into account that the concentration of other elements decreased in the previous purification step and $\mathrm{OH}^{-}$and $\mathrm{CO}_{3}{ }^{2-}$ ions concentrations in the aqueous solution increased.

Afterwards, the syrup generation and purification was based on a partial evaporation. For this reason, the concentration of almost all the elements plotted in Figure 4 and Figure 5 notably increased. However, this effect was much more significant when the non-purified syrup (sample G, Figure 1) was converted into EP2 (sample H, Figure 1) by evaporation, centrifugation and crystallization. This was basically caused because, during the crystallization of sugars, metals remained in the solution and the residual syrup (EP2) was enriched in these contaminants. The elemental enrichment factors caused by this evaporation step were included within the 4 to 7 range.

The concentrations found in the final product were in the order of hundreds of $\mu \mathrm{gg}^{-1}$ for $\mathrm{Na}, \mathrm{K}, \mathrm{Mg}$ and $\mathrm{Ca}$, and tens of $\mu \mathrm{g} \mathrm{kg}{ }^{-1}$ for the remaining analytes. These results suggested that distillation was an effective process in terms of metals removal since the concentrations found in EP2 were lowered by a factor higher than 1000 in the final bioethanol. In other words, more than $99.9 \%$ of the metals present in EP2 remained in 
the vinasse, which is exploited as fertilizer or animal feeding $[28,29]$. It can be observed that concentrations for $\mathrm{Na}, \mathrm{K}$ (Figure 4.a), Co, Ni, Sb and Mo (Figure 5) drastically decreased in this point due to precipitation of some metals after distillation. Anyhow, it is not easy to obtain a clear conclusion in this point as the quality of the raw material is not continuous over the time of the process due to collection of sugar beet obtained from various soils and contaminated with soils particles. .

It is noteworthy that no significant differences were observed between the samples coming from the beginning and the end of the production campaign, except the difference between both set of samples in terms of the fraction of metals extracted by slicing and this derived from the extraction with hot water, which has been previously discussed in this section of the paper.

Finally, when processes for the two evaluated refineries studied were compared, it was concluded that not significant differences were observed between them in terms of evolution of metal concentration along both processes. As regards the elemental concentrations, for major elements, there were not remarkable differences as a function of the raw material. However, the content for trace metals slightly differed for both raw materials. This may be due to differences in the composition of soil where raw materials developed.

It is also interesting to compare the metal contamination reported in the literature for bioethanol $[4,12,13,15]$ and the elements found in the samples analyzed in the present work, collected in these two processes. Most of the elements reported in the literature are initially present in the fermentation step and the transfer of a very small percentage (lower than 0.01\%) is observed in the final bioethanol. Sánchez et al. 
$[12,13]$ reported hundreds of $\mathrm{ng} \mathrm{mL}^{-1}$ of $\mathrm{Na}$ and $\mathrm{K}$, and tens of $\mathrm{ng} \mathrm{mL}^{-1}$ of $\mathrm{Ca}$ and $\mathrm{Mg}$ in bioethanol samples. In the same work, some trace elements such as $\mathrm{Mn}, \mathrm{Cu}, \mathrm{Fe}$ or $\mathrm{Ni}$ were found only in some bioethanol samples in concentrations ranging from 1 to $20 \mathrm{ng}$ $\mathrm{mL}^{-1}$ and other minor elements found in the samples studied in this work, such as $\mathrm{Cd}$, $\mathrm{Co}, \mathrm{Mo}, \mathrm{Pb}$ or $\mathrm{Sb}$, were below the LOQ in all bioethanol samples reported. $[12,13] \mathrm{On}$ the other hand, $\mathrm{Zn}$ concentrations of hundreds of $\mathrm{ng} \mathrm{mL^{-1 }}$ were reported in two bioethanol samples [12]. However, $\mathrm{Zn}$ is not a major element in the samples analyzed in this work. Therefore, bioethanol samples could also suffer metal contamination after their production, during their storage and transport.

\section{Conclusions.}

Our initial review [4] of the literature on the bioethanol contamination and analysis and previous works carried out in the research group $[12,13]$ has shown that some elements were systematically observed in the bioethanol produced. In order to verify the potential source of these pollutants, the tracking of metals found in bioethanol samples has been carried out along the production process by means of the use of an analytical method based on ICP-MS after samples microwave digestion, previously validated through the analysis of a biomass CRM and recovery tests. Metals encountered in bioethanol samples have been monitored and they were found in the raw material at concentrations from three to five orders of magnitude higher than those found in the final product. During the bioethanol production process, the liming and carbonatation operations are effective to remove partially metals that can form insoluble hydroxides and carbonates, respectively. However, those elements with high 
solubility product or present at low concentrations are not removed by this way and their concentrations in the syrups samples increase drastically due to the water evaporation. Finally, during the distillation, metals concentrations decreases by a factor of 1000-10000, showing the effective decontamination of the final bioethanol. It should be mentioned that not important external sources of pollution were discovered along this process, being the most important source of pollution the use of nontreated water that incorporates $\mathrm{Ca}$ and $\mathrm{Mg}$. However, this pollution is quantitatively removed during the distillation step.

According to these results, it could be concluded that the main origin of metals in bioethanol commercially available is the raw material, although the steps of the process for removing metals (liming, carbonatation and distillation) seem to be effective, being the distillation the most important and effective operation in terms of metals removal. However, other contamination sources cannot be completely discarded since samples could also be polluted during their storage and transport.

\section{Acknowledgements}

The authors wish to acknowledge UNGDA for the samples provided to carry out this work. C. Sánchez thanks the Ministry of Education, Culture and Sports, Spain for the grant FPU 13/01438 and IFPEN for financial support. 
References

[1] Demirbas A. Competitive liquid biofuels from biomass. Appl Energy 2011;88:1728. doi:10.1016/j.apenergy.2010.07.016.

[2] Köpke M, Dürre P. Biochemical production of bioethanol. Handb. biofuels Prod. Process. Technol., Woodhead Publishing Limited; 2011, p. 221-257. doi:10.1533/9780857090492.2.199.

[3] Walker GM. Bioethanol: Science and technology of fuel alcohol. Ventus Publishing ApS; 2010.

[4] Sánchez R, Sánchez C, Lienemann C-P, Todolí J-L. Metal and metalloid determination in biodiesel and bioethanol. J Anal At Spectrom 2015;30:64-101. doi:10.1039/C4JA00202D.

[5] Monot F, Margeot A, Hahn-Hägerdal B, Lindstedt J, Slade R. The NILE Project Advances in the Conversion of Lignocellulosic Materials into Ethanol. Oil Gas Sci Technol - Rev d'IFP Energies Nouv 2013;68:693-705. doi:10.2516/ogst/2012078.

[6] Lemos P, Mesquita FC. Future of Global Bioethanol: An Appraisal of Results, Risk and Uncertainties. Glob. Bioethanol, Elsevier Inc.; 2016, p. 221-37. doi:10.1016/B978-0-12-803141-4.00011-3.

[7] Nigam PS, Singh A. Production of liquid biofuels from renewable resources. Prog Energy Combust Sci 2011;37:52-68. doi:10.1016/j.pecs.2010.01.003.

[8] Fargione J, Hill J, Tilman D, Polasky S, Hawthorne P. Land Clearing and the Biofuel Carbon Debt. Science (80- ) 2008;319:1235-8. 
doi:10.1126/science.1152747.

[9] Ho DP, Ngo HH, Guo W. A mini review on renewable sources for biofuel. Bioresour Technol 2014;169:742-9. doi:10.1016/j.biortech.2014.07.022.

[10] Patil V, Tran KQ, Giselrød HR. Towards sustainable production of biofuels from microalgae. Int J Mol Sci 2008;9:1188-95. doi:10.3390/ijms9071188.

[11] Habe H, Shinbo T, Yamamoto T, Sato S, Shimada H, Sakaki K. Chemical Analysis of Impurities in Diverse Bioethanol Samples. J Japan Pet Inst 2013;56:414-22.

[12] Sánchez C, Lienemann C-P, Todolí J-L. Analysis of bioethanol samples through Inductively Coupled Plasma Mass Spectrometry with a total sample consumption system. Spectrochim Acta - Part B At Spectrosc 2016;124. doi:10.1016/j.sab.2016.08.018.

[13] Sánchez C, Lienemann C-P, Todolí J-L. Metal and metalloid determination in bioethanol through inductively coupled plasma-optical emission spectroscopy. Spectrochim Acta Part B At Spectrosc 2016;115:16-22. doi:10.1016/j.sab.2015.10.011.

[14] Chiche D, Diverchy C, Lucquin AC, Porcheron F, Defoort F. Synthesis Gas Purification. Oil Gas Sci Technol - Rev d'IFP Energies Nouv 2013;68:707-23. doi:10.2516/ogst/2013175.

[15] Donati GL, Amais RS, Schiavo D, Nóbrega J a. Determination of $\mathrm{Cr}, \mathrm{Ni}, \mathrm{Pb}$ and $\mathrm{V}$ in gasoline and ethanol fuel by microwave plasma optical emission spectrometry. J Anal At Spectrom 2013;28:755. doi:10.1039/c3ja30344f.

[16] Saint'Pierre TD, Frescura VLA, Curtius AJ. The development of a method for the 
determination of trace elements in fuel alcohol by ETV-ICP-MS using isotope dilution calibration. Talanta 2006;68:957.

[17] Dias JC, Kubota LT, Nesterenko PN, Dicinoski GW, Haddad PR. A new highperformance chelation ion chromatographic system for the direct determination of trace transition metals in fuel ethanol. Anal Methods 2010;2:1565. doi:10.1039/c0ay00417k.

[18] Saint'Pierre TD, Maranhão TDA, Frescura VLA, Curtius AJ. The development of a method for the determination of trace elements in fuel alcohol by electrothermal vaporization-inductively coupled plasma mass spectrometry using external calibration. Spectrochim Acta - Part B At Spectrosc 2005;60:605.

[19] Alves VN, Mosquetta R, Coelho NMM, Bianchin JN, Di Pietro Roux KC, Martendal E, et al. Determination of cadmium in alcohol fuel using Moringa oleifera seeds as a biosorbent in an on-line system coupled to FAAS. Talanta 2010;80:1133-8. doi:10.1016/j.talanta.2009.08.040.

[20] Tormen L, Chaves ES, Saint'Pierre TD, Frescura VL a., Curtius AJ. Determination of trace elements in fuel ethanol by ICP-MS using direct sample introduction by a microconcentric nebulizer. J Anal At Spectrom 2008;23:1300.

[21] Santos LN, Neto JAG, Caldas NM. Simultaneous determination of $\mathrm{Cu}$ and $\mathrm{Pb}$ in fuel ethanol by graphite furnace AAS using tungsten permanent modifier with co-injection of Ir. Fuel 2012;99:9-12. doi:10.1016/j.fuel.2012.04.024.

[22] Roldan PS, Alcântara IL, Castro GR, Rocha JC, Padilha CCF, Padilha PM. Determination of $\mathrm{Cu}, \mathrm{Ni}$, and $\mathrm{Zn}$ in fuel ethanol by FAAS after enrichment in 
column packed with 2-aminothiazole-modified silica gel. Anal Bioanal Chem 2003;375:574.

[23] Vieira EG, Soares I V, Dias Filho NL, da Silva NC, Garcia EF, Bastos AC, et al. Preconcentration and determination of metal ions from fuel ethanol with a new 2,2'-dipyridylamine bonded silica. J Colloid Interface Sci 2013;391:116-24. doi:10.1016/j.jcis.2012.08.073.

[24] Leijenhorst EJ, Wolters W, Van De Beld L, Prins W. Inorganic element transfer from biomass to fast pyrolysis oil: Review and experiments. Fuel Process Technol 2016;149:96-111. doi:10.1016/j.fuproc.2016.03.026.

[25] Vintila T, Negrea A, Barbu H, Sumalan R, Kovacs K. Metal distribution in the process of lignocellulosic ethanol. J Chem Technol Biotechnol 2016;91:1607-14. doi:10.1002/ps.4902.

[26] Vassilev S V., Baxter D, Andersen LK, Vassileva CG. An overview of the chemical composition of biomass. Fuel 2010;89:913-33. doi:10.1016/j.fuel.2009.10.022.

[27] Douglas RW, El-Shamy TMM. Reactions of Glasses with Aqueous Solutions. J Am Ceram Soc 1967;50:1-8. doi:10.1111/j.1151-2916.1967.tb14960.x.

[28] Christofoletti CA, Escher JP, Correia JE, Marinho JFU, Fontanetti CS. Sugarcane vinasse: Environmental implications of its use. Waste Manag 2013;33:2752-61. doi:10.1016/j.wasman.2013.09.005.

[29] Madejón E, López R, Murillo JM, Cabrera F. Agricultural use of three (sugar-beet) vinasse composts: Effect on crops and chemical properties of a Cambisol soil in the Guadalquivir river valley (SW Spain). Agric Ecosyst Environ 2001;84:55-65. 
doi:10.1016/S0167-8809(00)00191-2. 


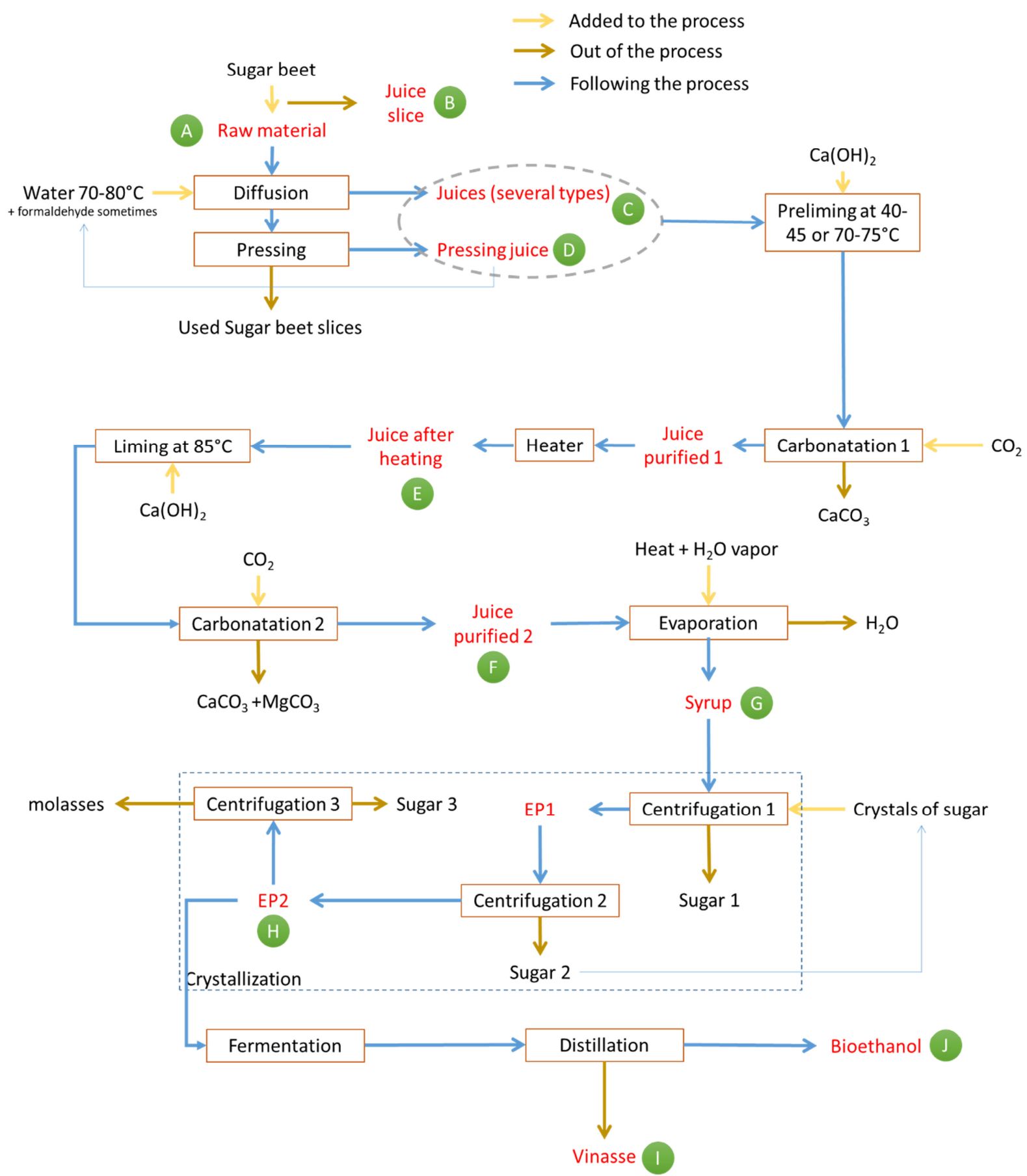

Figure 1. Scheme of bioethanol production process studied in the present work. 


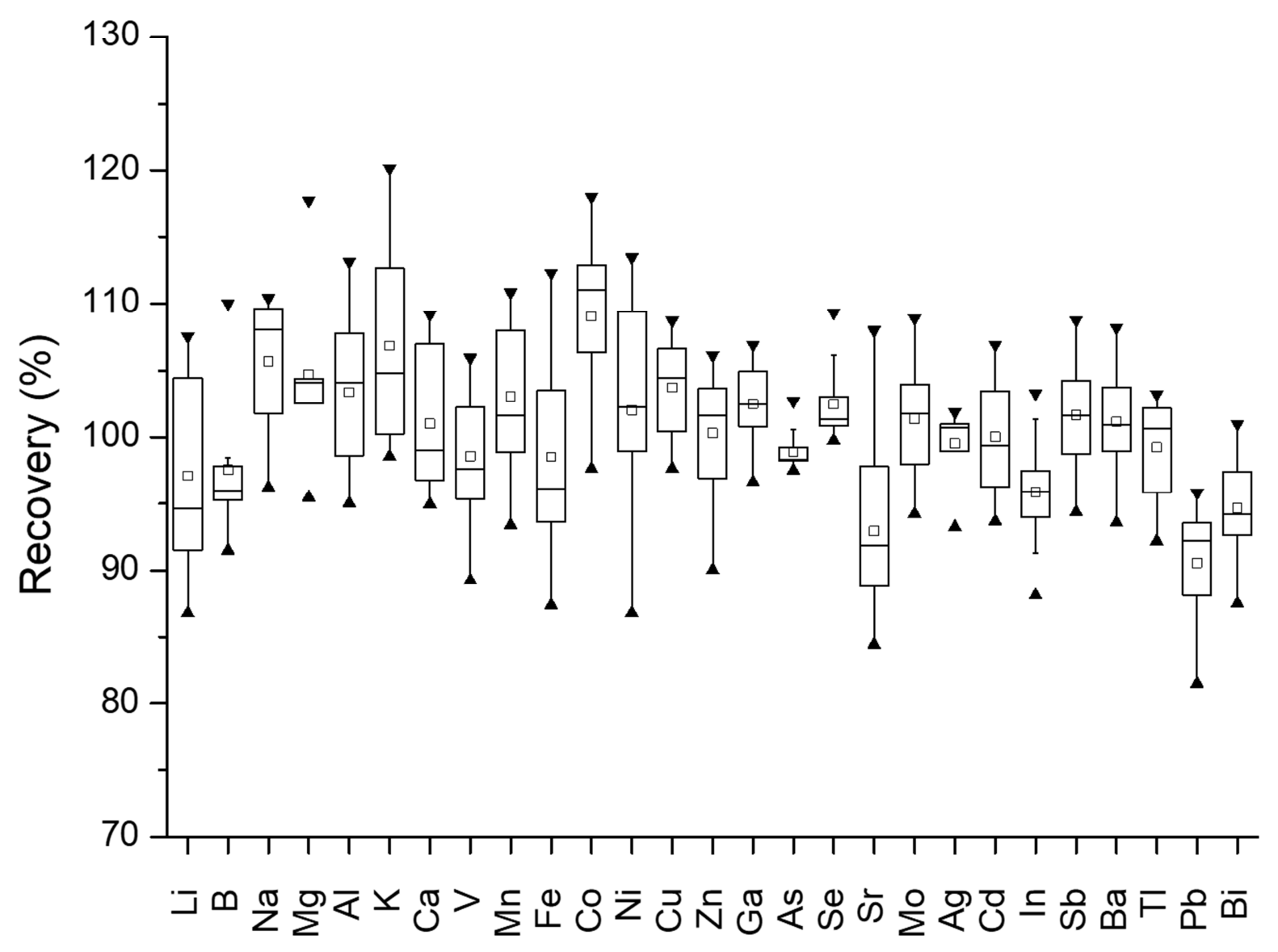

Figure 2. Recoveries obtained for twelve spiked samples. Empty squares: average recovery; boxes: recoveries ranged from percentile $25 \%$ to percentile $75 \%$; full triangles: maximum and minimum recovery obtained for each element. 
(a) 12

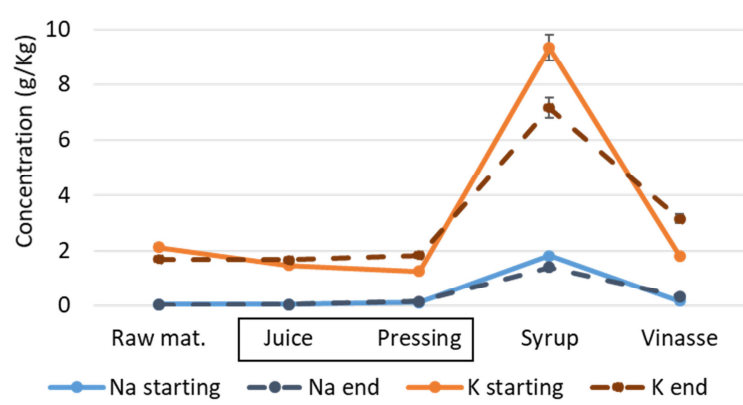

(c) 35

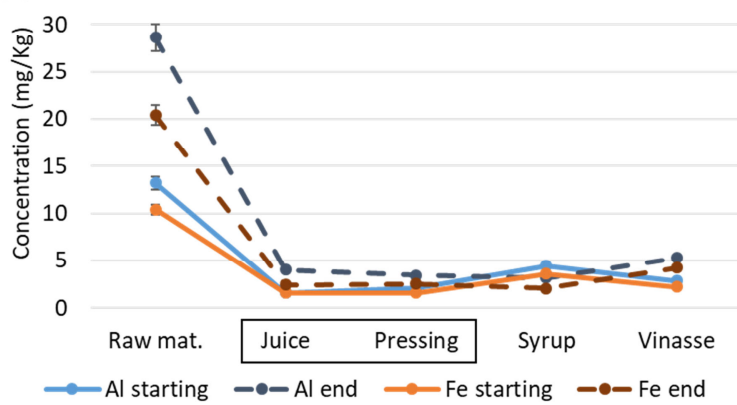

(e) 7

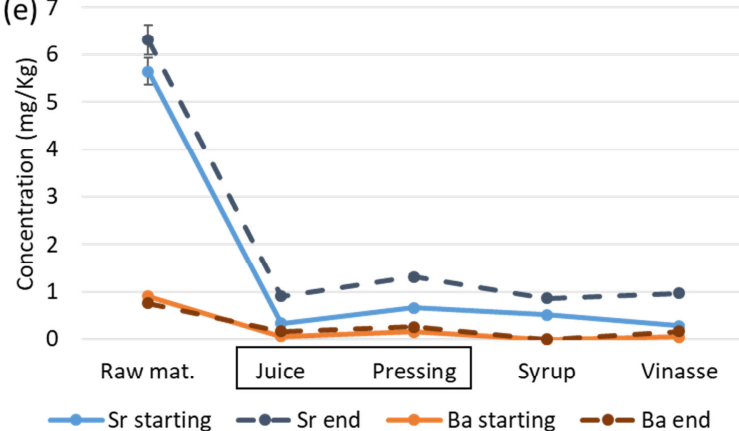

(g) 100

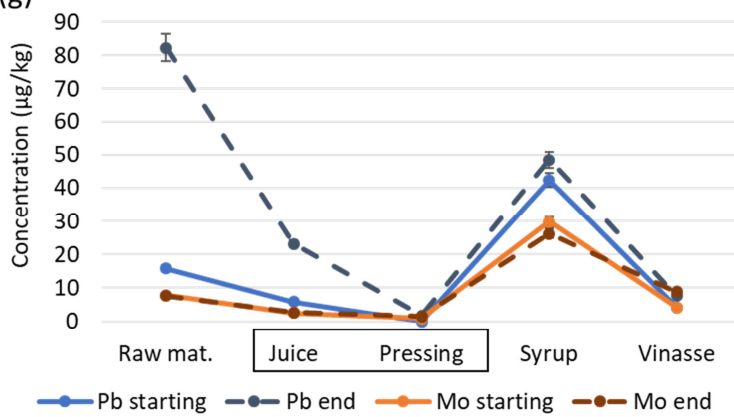

(b) 2.5

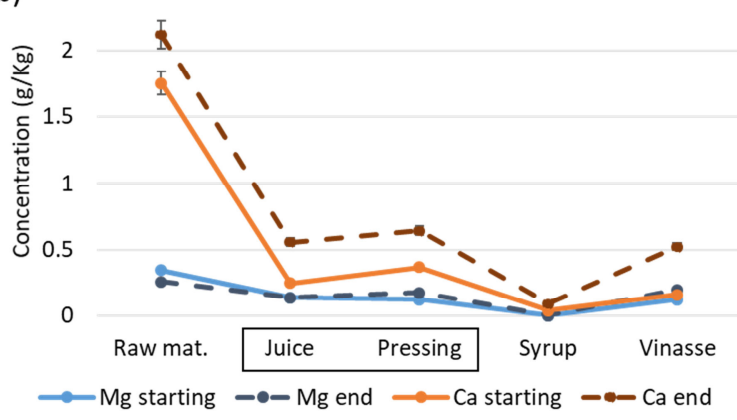

(d) 6

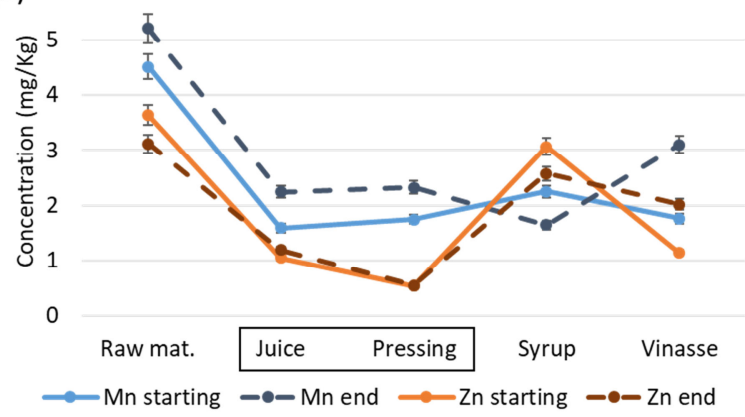

(f) 180

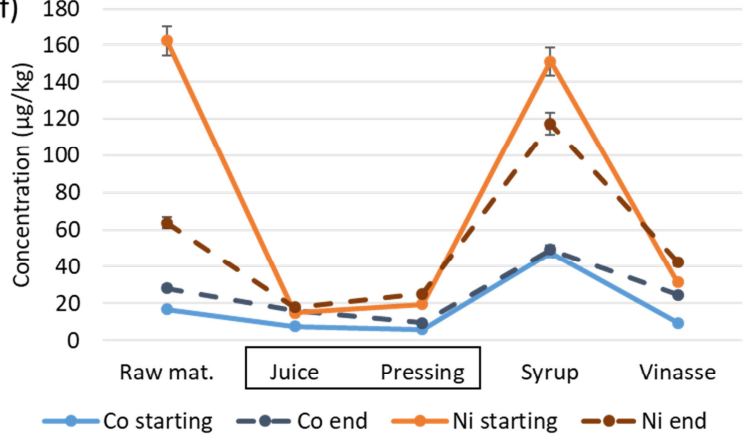

(h) 30

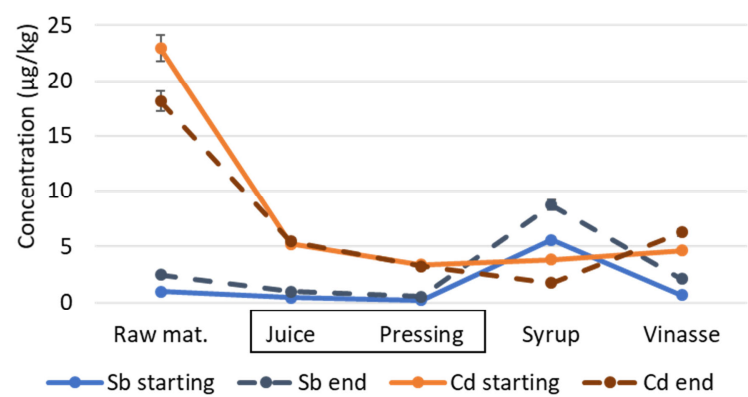

Figure 3. Evolution of metals along bioethanol production process at the beginning and at the end of the campaign. Sugar factory 1. (a) $\mathrm{Na}$ and $\mathrm{K}$, (b) $\mathrm{Ca}$ and $\mathrm{Mg}$, (c) $\mathrm{Al}$ and $\mathrm{Fe}$, (d) Mn and $\mathrm{Zn}$, (e) Sr and Ba, (f) Cu and Ga, (g) Co and Ni, (h) Pb and Sb. 
(a)

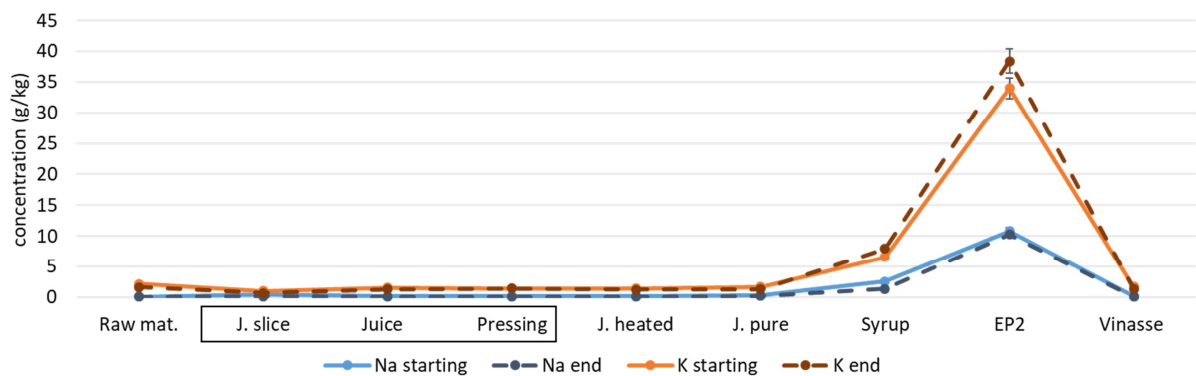

(b) 1.4

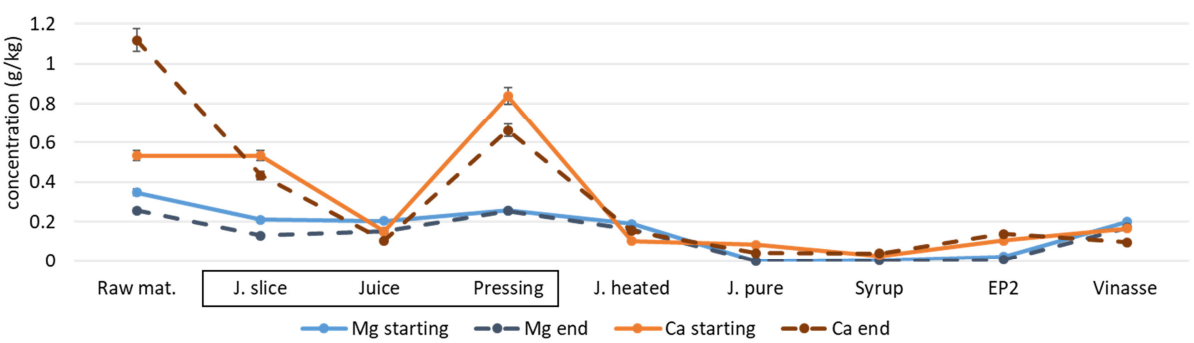

(c) 300

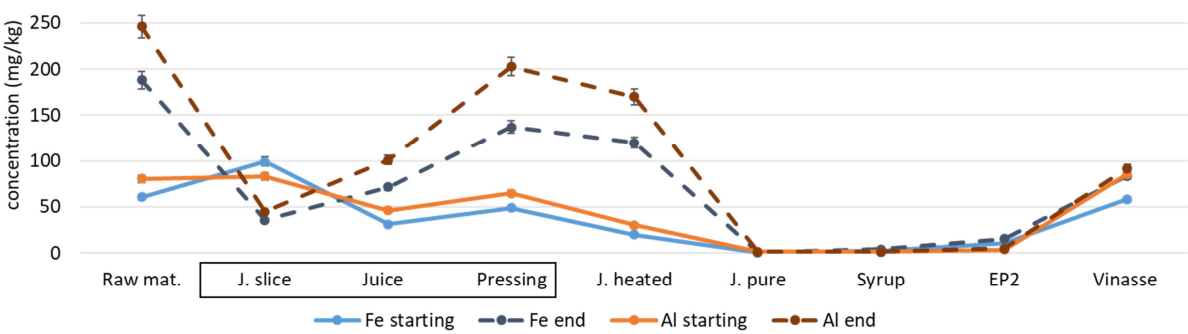

(d) 3.5

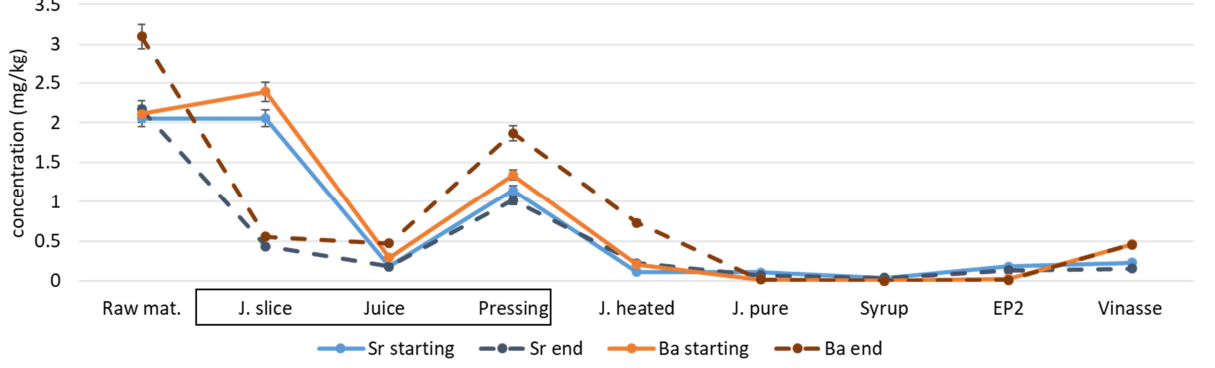

(e) 25

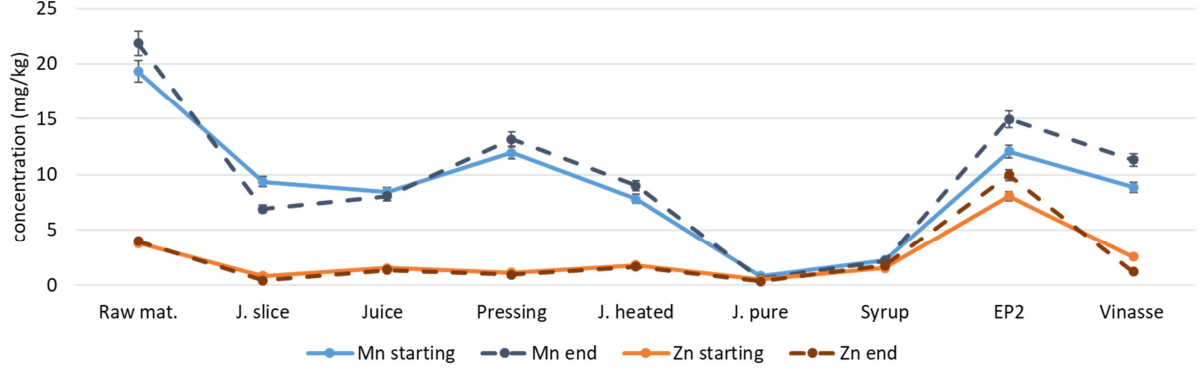

Figure 4. Evolution of major metals along bioethanol production process at the beginning and at the end of the campaign of Sugar factory 2. (a) $\mathrm{Na}$ and $\mathrm{K}$, (b) $\mathrm{Ca}$ and $\mathrm{Mg}$, (c) Al and Fe, (d) Sr and Ba and (e) Mn and Zn. 
(a) 3000

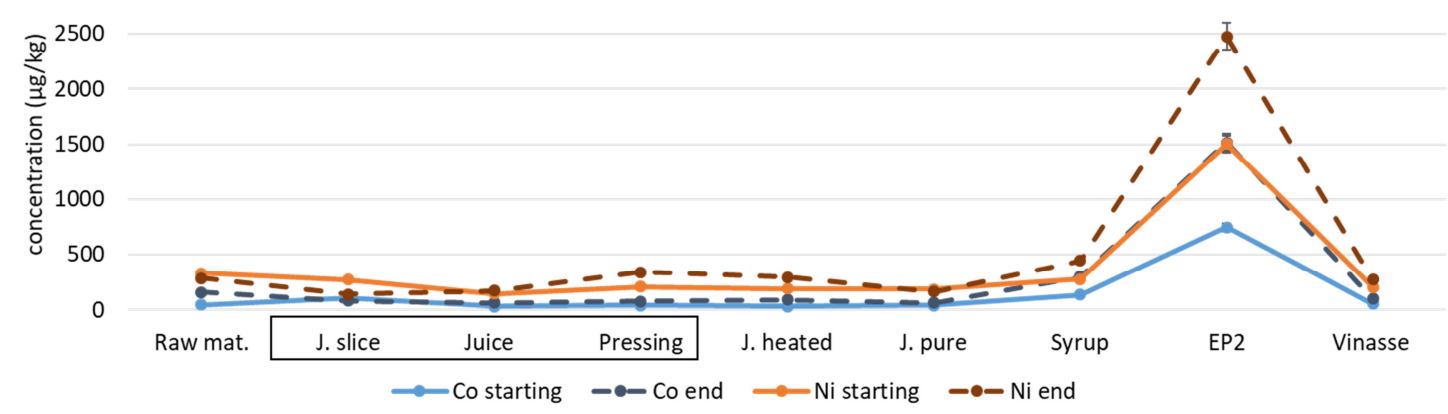

(b) 100

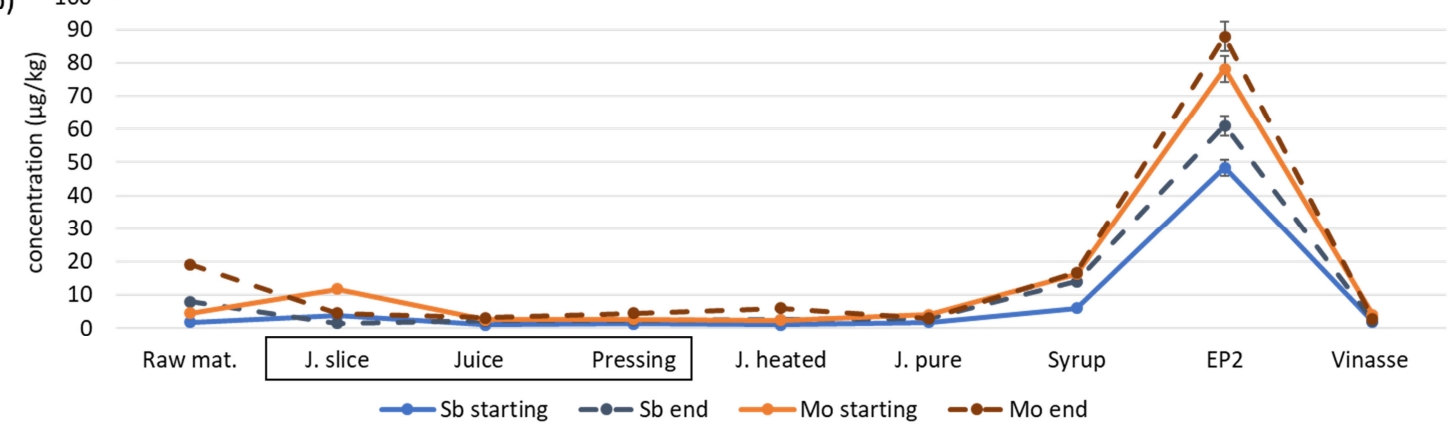

Figure 5. Evolution of minor metals along bioethanol production process at the beginning and at the end of the campaign of Sugar factory 2. (a) Co and $\mathrm{Ni}$, (b) Sb and Mo. 
Table 1. ICP-MS operating conditions.

\begin{tabular}{|c|c|c|}
\hline \multicolumn{3}{|c|}{ Plasma } \\
\hline \multirow{4}{*}{ Ar flow rates $/ \mathrm{L} \mathrm{min}^{-1}$} & \multicolumn{2}{|c|}{ Plasma gas: 15.0} \\
\hline & \multicolumn{2}{|c|}{ Auxiliary gas: 0.9} \\
\hline & \multicolumn{2}{|c|}{ Nebulizer: 0.35} \\
\hline & \multicolumn{2}{|c|}{ HMI: 0.56} \\
\hline RF power/W & \multicolumn{2}{|c|}{1600} \\
\hline Sampling depth/mm & \multicolumn{2}{|c|}{10} \\
\hline \multicolumn{3}{|c|}{ Acquisition conditions } \\
\hline Liquid flow rate $/ \mu \mathrm{L} \mathrm{min}^{-1}$ & \multicolumn{2}{|c|}{300} \\
\hline Number of replicates & \multicolumn{2}{|c|}{3} \\
\hline Integration time/s & \multicolumn{2}{|c|}{0.3} \\
\hline Sweeps per replicate & \multicolumn{2}{|c|}{100} \\
\hline \multicolumn{3}{|c|}{ Collision cell } \\
\hline He flow rate $/ \mathrm{mL} \mathrm{min}^{-1}$ & \multicolumn{2}{|c|}{4.3} \\
\hline OctP Bias/V & \multicolumn{2}{|c|}{-18.0} \\
\hline Oct RF/V & \multicolumn{2}{|c|}{200} \\
\hline Energy discrimination/V & \multicolumn{2}{|c|}{3.0} \\
\hline \multicolumn{3}{|c|}{ Measured isotopes } \\
\hline \multicolumn{3}{|c|}{ 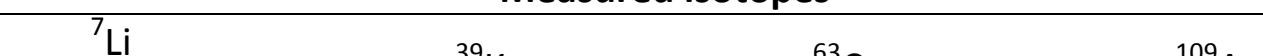 } \\
\hline \multicolumn{3}{|r|}{${ }^{111} \mathrm{Ag}$} \\
\hline \multicolumn{3}{|l|}{${ }^{23} \mathrm{Na}$} \\
\hline \multicolumn{3}{|c|}{${ }^{55} \mathrm{Mn}$} \\
\hline \multicolumn{3}{|c|}{${ }^{56} \mathrm{Fe}$} \\
\hline \multicolumn{3}{|c|}{${ }^{59} \mathrm{Co}$} \\
\hline${ }^{11} \mathrm{P}$ & ${ }^{95} \mathrm{Mo}$ & ${ }^{208} \mathrm{~Pb}$ \\
\hline
\end{tabular}


Table 2. Found concentrations for the CRM DC73349 through four different digestion methods.*

\begin{tabular}{|c|c|c|c|c|c|}
\hline $\begin{array}{c}\text { Conc. (mg } \\
\mathrm{kg}^{-1} \text { ) }\end{array}$ & Certified conc. & $\mathrm{MW} \mathrm{HNO}_{3}$ & $\begin{array}{c}\mathrm{MW} \mathrm{HNO}{ }_{3}+\mathrm{H}_{2} \mathrm{O}_{2} \\
(7: 1)\end{array}$ & $\begin{array}{c}\mathrm{MW} \mathrm{HNO}+\mathrm{HCl} \\
(6: 2)\end{array}$ & $\begin{array}{c}\text { Conventional } \\
\mathrm{HNO}_{3}\end{array}$ \\
\hline $\mathrm{Al}$ & $580 \pm 30$ & $569 \pm 12$ & $597 \pm 5$ & $559 \pm 8$ & $541 \pm 6$ \\
\hline $\mathrm{B}$ & $9.6 \pm 0.2$ & $8.2 \pm 0.3$ & $3.1 \pm 0.4$ & $4.1 \pm 0.4$ & $126 \pm 2$ \\
\hline $\mathrm{Ba}$ & $6.0 \pm 0.2$ & $5.85 \pm 0.17$ & $6.06 \pm 0.07$ & $6.66 \pm 0.05$ & $43.1 \pm 0.4$ \\
\hline $\mathrm{Ca}$ & $2500 \pm 100$ & $2278 \pm 38$ & $2367 \pm 25$ & $2346 \pm 27$ & $2240 \pm 23$ \\
\hline $\mathrm{Cd}$ & $0.233 \pm 0.004$ & $0.242 \pm 0.010$ & $0.240 \pm 0.006$ & $0.252 \pm 0.013$ & $0.248 \pm 0.011$ \\
\hline $\mathrm{Co}$ & $0.061 \pm 0.002$ & $0.065 \pm 0.002$ & $0.060 \pm 0.002$ & $0.061 \pm 0.003$ & $0.053 \pm 0.002$ \\
\hline $\mathrm{Cu}$ & $2.8 \pm 0.2$ & $2.76 \pm 0.06$ & $2.79 \pm 0.02$ & $2.99 \pm \pm 0.04$ & $0.93 \pm 0.02$ \\
\hline $\mathrm{Fe}$ & $46 \pm 2$ & $46.6 \pm 1.0$ & $46.2 \pm 0.4$ & $44 \pm 1.0$ & $38.4 \pm 0.8$ \\
\hline $\mathrm{K}$ & $4170 \pm 70$ & $4161 \pm 60$ & $4284 \pm 45$ & $4207 \pm 42$ & $4226 \pm 50$ \\
\hline $\mathrm{Mg}$ & $1060 \pm 170$ & $1004 \pm 16$ & $1015 \pm 10$ & $1019 \pm 11$ & $994 \pm 15$ \\
\hline $\mathrm{Mn}$ & $488 \pm 12$ & $480 \pm 11$ & $481 \pm 7$ & $482 \pm 6$ & $494 \pm 4$ \\
\hline $\mathrm{N}$ & $1.47 \pm 0.10$ & $1.63 \pm 0.05$ & $1.44 \pm 0.03$ & $1.40 \pm 0.03$ & $1.27 \pm 0.04$ \\
\hline $\mathrm{Na}$ & $63.0 \pm 1.0$ & $84.9 \pm 1.3$ & $89.8 \pm 1.4$ & $101 \pm 5$ & $211 \pm 3$ \\
\hline $\mathrm{P}$ & $1070 \pm 80$ & $1049 \pm 20$ & $1099 \pm 8$ & $1043 \pm 10$ & $1063 \pm 7$ \\
\hline $\mathrm{Se}$ & $0.099 \pm 0.004$ & $0.089 \pm 0.019$ & $0.10 \pm 0.03$ & $0.09 \pm 0.04$ & $0.14 \pm 0.03$ \\
\hline $\mathrm{Zn}$ & $38 \pm 2$ & $38.0 \pm 0.5$ & $37.5 \pm 0.5$ & $40.9 \pm 0.3$ & $33.8 \pm 0.5$ \\
\hline $\mathrm{Confiden}$ & $1 n+27 a 15(\mathrm{~N}=3$ & $\alpha=0.05)$ & & & \\
\hline
\end{tabular}

*Confidence intervals ( $N=3$ and $\alpha=0.05$ ) 
Table 3. Found concentrations for the CRM SRM 1575a through four digestion method studied.*

\begin{tabular}{|c|c|c|c|c|c|}
\hline $\begin{array}{c}\text { Conc. (mg } \\
\mathrm{kg}^{-1} \text { ) }\end{array}$ & Certified conc. & $\mathrm{MW} \mathrm{HNO}_{3}$ & $\begin{array}{c}\mathrm{MW} \mathrm{HNO} \mathrm{HN}_{3}+\mathrm{H}_{2} \mathrm{O}_{2} \\
(7: 1)\end{array}$ & $\begin{array}{c}\mathrm{MW} \mathrm{HNO}_{3}+\mathrm{HCl} \\
(6: 2)\end{array}$ & $\begin{array}{c}\text { Conventional } \\
\mathrm{HNO}_{3}\end{array}$ \\
\hline As & $1.25 \pm 0.15$ & $1.23 \pm 0.18$ & $1.23 \pm 0.04$ & $1.20 \pm 0.03$ & $1.06 \pm 0.03$ \\
\hline B & $38 \pm 6$ & $41 \pm 2$ & $37 \pm 2$ & $43 \pm 2$ & $<\mathrm{LOQ}$ \\
\hline $\mathrm{Ba}$ & $18 \pm 2$ & $19.2 \pm 0.2$ & $21.0 \pm 0.2$ & $15.2 \pm 0.2$ & $<\mathrm{LOQ}$ \\
\hline $\mathrm{Ca}$ & $16800 \pm 1100$ & $15901 \pm 181$ & $16660 \pm 202$ & $15771 \pm 216$ & $16381 \pm 199$ \\
\hline Co & $0.41 \pm 0.05$ & $0.389 \pm 0.003$ & $0.397 \pm 0.06$ & $0.401 \pm 0.009$ & $0.331 \pm 0.003$ \\
\hline $\mathrm{Cu}$ & $6.6 \pm 0.8$ & $5.54 \pm 0.04$ & $6.09 \pm 0.07$ & $5.38 \pm 0.08$ & $3.75 \pm 0.07$ \\
\hline $\mathrm{Fe}$ & $1070 \pm 57$ & $941 \pm 9$ & $983 \pm 10$ & $996 \pm 14$ & $629 \pm 10$ \\
\hline K & $9200 \pm 1000$ & $9562 \pm 80$ & $9924 \pm 108$ & $9482 \pm 76$ & $9514 \pm 162$ \\
\hline $\mathrm{Li}$ & $2.6 \pm 0.4$ & $2.24 \pm 0.18$ & $2.3 \pm 0.4$ & $3.5 \pm 0.3$ & $2.1 \pm 0.3$ \\
\hline $\mathrm{Mg}$ & $4800 \pm 400$ & $4629 \pm 48$ & $4787 \pm 59$ & $4728 \pm 32$ & $4666 \pm 78$ \\
\hline $\mathrm{Mn}$ & $61 \pm 5$ & $66 \pm 2$ & $68 \pm 2$ & $68 \pm 2$ & $66 \pm 2$ \\
\hline Mo & $0.28 \pm 0.05$ & $0.271 \pm 0.005$ & $0.33 \pm 0.02$ & $0.309 \pm 0.010$ & $0.264 \pm 0.011$ \\
\hline $\mathrm{Na}$ & $19600 \pm 1800$ & $19464 \pm 145$ & $20079 \pm 274$ & $19920 \pm 251$ & $19635 \pm 267$ \\
\hline $\mathrm{Ni}$ & $1.7 \pm 0.3$ & $1.39 \pm 0.03$ & $1.51 \pm 0.05$ & $1.38 \pm 0.04$ & $1.21 \pm 0.03$ \\
\hline$P$ & $1000 \pm 40$ & $954 \pm 16$ & $1027 \pm 16$ & $922 \pm 12$ & $990 \pm 17$ \\
\hline $\mathrm{Pb}$ & $47 \pm 3$ & $50.5 \pm 0.3$ & $50.7 \pm 0.8$ & $50.1 \pm 0.9$ & $49.0 \pm 0.7$ \\
\hline$S$ & $7300 \pm 600$ & $8662 \pm 208$ & $9108 \pm 125$ & $8391 \pm 132$ & $8655 \pm 237$ \\
\hline $\mathrm{Sb}$ & $0.095 \pm 0.014$ & $0.083 \pm 0.003$ & $0.132 \pm 0.009$ & $0.108 \pm 0.004$ & $0.093 \pm 0.005$ \\
\hline $\mathrm{Se}$ & $0.12 \pm 0.02$ & $0.18 \pm 0.04$ & $0.21 \pm 0.03$ & $0.22 \pm 0.07$ & $0.16 \pm 0.05$ \\
\hline $\mathrm{Si}$ & $6000 \pm 700$ & $381 \pm 5$ & $923 \pm 7$ & $1506 \pm 47$ & $190 \pm 4$ \\
\hline $\mathrm{Sr}$ & $246 \pm 16$ & $255 \pm 2$ & $255 \pm 3$ & $252 \pm 2$ & $257 \pm 2$ \\
\hline V & $2.4 \pm 0.4$ & $1.7 \pm 0.2$ & $1.8 \pm 0.2$ & $1.9 \pm 0.2$ & $0.61 \pm 0.05$ \\
\hline $\mathrm{Zn}$ & $55 \pm 4$ & $58.2 \pm 0.5$ & $62.7 \pm 1.0$ & $57.5 \pm 0.5$ & $55.3 \pm 0.6$ \\
\hline
\end{tabular}

*Confidence intervals ( $N=3$ and $\alpha=0.05$ ) 
Table 4. Limits of detection (in $\mathrm{mg} \mathrm{kg}^{-1}$ ) obtained for real samples.

\begin{tabular}{ccccccccccc}
\hline Analyte & $\mathrm{Li}$ & $\mathrm{Be}$ & $\mathrm{B}$ & $\mathrm{Na}$ & $\mathrm{Mg}$ & $\mathrm{Al}$ & $\mathrm{Si}$ & $\mathrm{P}$ & $\mathrm{S}$ & $\mathrm{K}$ \\
\hline $\mathrm{LOD}\left(\mathrm{mg} \mathrm{Kg}^{-1}\right)$ & 0.16 & 0.18 & 2.7 & 1.0 & 0.07 & 0.2 & 14 & 0.7 & 354 & 2 \\
\hline Analyte & $\mathrm{Ca}$ & $\mathrm{V}$ & $\mathrm{Mn}$ & $\mathrm{Fe}$ & $\mathrm{Co}$ & $\mathrm{Ni}$ & $\mathrm{Cu}$ & $\mathrm{Zn}$ & $\mathrm{Ga}$ & $\mathrm{As}$ \\
\hline $\mathrm{LOD}\left(\mu \mathrm{g} \mathrm{kg}^{-1}\right)$ & 1.0 & 0.003 & 0.015 & 0.06 & 0.008 & 0.03 & 0.010 & 0.04 & 0.004 & 0.02 \\
\hline Analyte & $\mathrm{Se}$ & $\mathrm{Sr}$ & $\mathrm{Mo}$ & $\mathrm{Ag}$ & $\mathrm{Cd}$ & $\mathrm{In}$ & $\mathrm{Sb}$ & $\mathrm{Ba}$ & $\mathrm{Tl}$ & $\mathrm{Pb}$ \\
\hline $\mathrm{LOD}\left(\mu \mathrm{gg}^{-1}\right)$ & 2 & 0.004 & 0.002 & 0.002 & 0.005 & 0.002 & 0.0005 & 0.009 & 0.0004 & 0.002 \\
\hline
\end{tabular}

